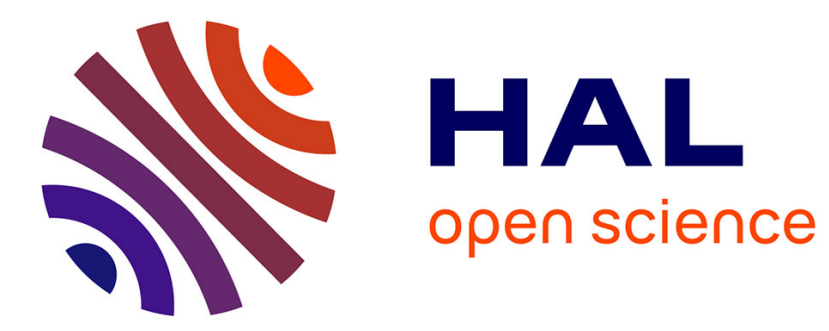

\title{
Surface states and magnetic heterogeneity in iron-based glasses
}

Chr. Janot, B. George

\section{To cite this version:}

Chr. Janot, B. George. Surface states and magnetic heterogeneity in iron-based glasses. Journal de Physique Lettres, 1985, 46 (2), pp.85-88. 10.1051/jphyslet:0198500460208500 . jpa-00232482

\section{HAL Id: jpa-00232482 https://hal.science/jpa-00232482}

Submitted on 1 Jan 1985

HAL is a multi-disciplinary open access archive for the deposit and dissemination of scientific research documents, whether they are published or not. The documents may come from teaching and research institutions in France or abroad, or from public or private research centers.
L'archive ouverte pluridisciplinaire HAL, est destinée au dépôt et à la diffusion de documents scientifiques de niveau recherche, publiés ou non, émanant des établissements d'enseignement et de recherche français ou étrangers, des laboratoires publics ou privés. 
Classification

Physics Abstracts

$61.40-61.12-81.60$

\title{
Surface states and magnetic heterogeneity in iron-based glasses
}

\author{
Chr. Janot \\ Institut Max von Laue - Paul Langevin, 156 X, 38042 Grenoble Cedex, France \\ and B. George
}

Physique du Solide (*), BP 239, 54506 Vandouvre-les-Nancy. France

(Reçu le 5 novembre 1984, accepté le 27 novembre 1984)

\begin{abstract}
Résumé. - Des mesures de diffusion des neutrons aux petits angles ont été réalisées sur des alliages amorphes de composition $\mathrm{Fe}_{70} \mathrm{Cr}_{5} \mathrm{P}_{15} \mathrm{C}_{10}$. L'utilisation de méthodes de variation de contraste (application d'un champ magnétique extérieur et/ou immersion dans un liquide deutéré) permet de séparer les intensités diffusées par les hétérogénéités magnétiques, les imperfections de surfaces et les éventuelles hétérogénéités atomiques en volume. On montre que cette dernière contribution peut être aussi faible que $2 \%$ de la contribution de surface qui elle-même peut ne représenter que $5 \%$ de la contribution magnétique. Une opération de polissage amplifie encore ces phénomènes.

Abstract. - Small angle neutron scattering experiments have been performed on amorphous $\mathrm{Fe}_{70} \mathrm{Cr}_{5} \mathrm{P}_{15} \mathrm{C}_{10}$ alloys. Contributions to SANS intensity due to magnetic heterogeneities, surface imperfections and possible bulk atomic heterogeneities have been obtained using contrast variation methods (application of an external magnetic field and/or immersion of the sample in a deuterated liquid). The bulk atomic scattering may be as small as $2 \%$ of that due to the surface, which in turn is less than $5 \%$ of that coming from magnetic heterogeneities. Polishing procedures amplify these phenomena still further.
\end{abstract}

\section{Introduction.}

Small angle neutron scattering (SANS) experiments have for several years been expected to produce the information needed concerning medium range order, density and composition fluctuation in amorphous alloys [1]. Detailed interpretation in terms of defects, namely quasi-dislocation effects, has even been proposed to account for the dependence of the scattered intensity on a negative $q$ power law $[2,3]$. This might have been jumping too fast to a desired conclusion. Obviously, amorphous ribbons have a quite large surface-to-bulk ratio and surface imperfections have been known to contribute to SANS signals [4]. In a recent paper this drastic effect has been elegantly confirmed in the case of $\mathrm{Pd}_{80} \mathrm{Si}_{20}$ amorphous alloys [5]. Additional scattering may come from magnetic heterogeneity [6] if iron-based glasses are concerned. It is the purpose of

$\left(^{*}\right)$ Laboratoire associé au CNRS, no 155. 
this paper to show that investigating bulk heterogeneity in $\mathrm{Fe}_{70} \mathrm{Cr}_{5} \mathrm{P}_{15} \mathrm{C}_{10}$ amorphous alloys using the SANS approach is not really straightforward and that careful analyses of both magnetic and surface effects [7] have to be carried out before concluding to the existence of quasi-dislocations or other bulk influences.

\section{Experiments and results.}

Amorphous $\mathrm{Fe}_{70} \mathrm{Cr}_{5} \mathrm{P}_{15} \mathrm{C}_{10}$ alloys have been obtained by the melt spinning technique in the form of ribbons $35 \mu \mathrm{m}$ thick and $10 \mathrm{~mm}$ wide. The particular composition has been chosen in relation to the mechanical properties and surface studies as previously reported [7]. SANS was measured on the D11 camera at the ILL Grenoble with a sample-to-detector distance of $10.6 \mathrm{~mm}$ and using cold neutrons of $7 \AA$ wavelength. The corresponding scattering vector range $q=\frac{4 \pi}{\lambda} \sin \theta$ is $0.4 \times 10^{-3}$ to $3 \times 10^{-3} \AA^{-1}$. The investigated samples correspond to 60 ribbon pieces stacked together with their surfaces perpendicular to the incident beam and the largest dimension in the vertical position. Experimental raw data were corrected for background and detector-cell efficiency as usual. A horizontal magnetic field (up to about $1.4 \mathrm{~T}$ ) was applied, if desired, parallel to the surface of the ribbons. The samples were placed in a quartz cell in which they could be immersed in heavy water $\mathrm{D}_{2} \mathrm{O}$ whose scattering length per unit volume $\left(b=6.37 \times 10^{10} \mathrm{~cm}^{3}\right)$ happens to be very close to that of the material studied $(\langle b\rangle \simeq 6.41 \times$ $10^{10} \mathrm{~cm}^{3}$ ). Indeed by applying a strong external magnetic field one can expect to eliminate any SANS contribution from magnetic inhomogeneity in the samples and immersing the samples in heavy water suppresses any surface imperfection effects by annihilation of contrast between the samples and the outside. One disadvantage of using heavy water is that good surface wetting requires careful previous cleaning. The great advantage of using such a pure deuterated liquid is the absence of large incoherent background that would appear with the hydrogenated counterpart [5]. SANS signal from the sample in zero magnetic field and without heavy water in the cell includes possible contributions from the bulk. the surface and magnetic inhomogeneity. In the presence of a sufficiently large magnetic field, but still without heavy water in the cell, we are left with atomic inhomogeneity and surface imperfections. SANS with the applied field and with the heavy water gives the pure contributions from atomic bulk inhomogeneity (both density and concentration fluctuation). In conclusion it is possible to extract the three individually mentioned contributions to the SANS signals from a set of three experiments on each sample. Typical results obtained from SANS measurements on as-cast ribbon of the $\mathrm{Fe}_{70} \mathrm{Cr}_{5} \mathrm{P}_{15} \mathrm{C}_{10}$ glass are shown in figure 1 in which the surface signal is compared to the magnetic signal (Fig. 1a) and the volume signal to the surface signal (Fig. 1b). The crude conclusion that follows is that of the whole SANS signal, about $95 \%$ comes from magnetic inhomogeneity, $5 \%$ is due to surface imperfections and a mere $0.1 \%$ fraction, hardly emerging from the background, can be attributed to bulk nonmagnetic inhomogeneity.

For the sake of comparison with previously reported data [2, 3], figure 2 shows an alternative representation of the data, namely $\ln I v s$. $\ln q$ for both the magnetic and the surface contributions to SANS signal. These plots exhibit linear behaviour whose slopes are respectively not too far from -4 and -3 (obviously without any possible references to quasi-dislocation effects !). From estimated values of the intercepts of these linear parts with the ordinate axis it is possible to suggest that the "magnetic particles " concerned are about 10 times smaller than the surface imperfections whose radius of gyration, as deduced from a Guinier plot, is of the order of $200 \AA$.

In the hope of improving the surfaces, the ribbons were electrochemically polished prior to SANS measurements. As already reported [5], the surface signal is disappointingly increased by a factor of about 2 (see Fig. 3a), and surprisingly enough, the magnetic signal is also increased by even a larger factor of about 4 (Fig. 3b). 


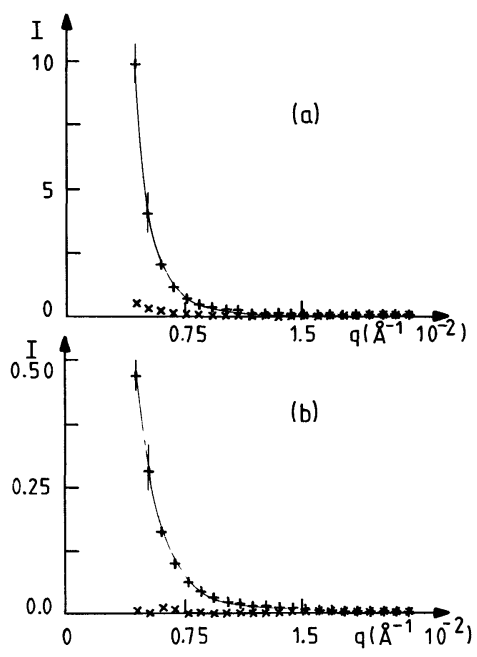

Fig. 1. - (a) SANS intensity due to magnetic heterogeneity $(+)$ compared to that due to surface imperfections $(x)$. (b) SANS from bulk atomic heterogeneity $(x)$ compared to the contribution from surface imperfections $(+)$. (Note the scale difference on the ordinate axes in Fig. 1a and Fig. 1b).

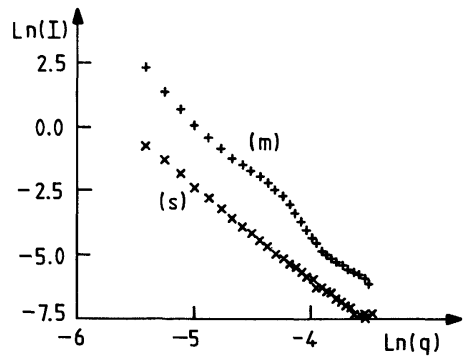

Fig. 2. - Double logarithmic plot of $I(q)$ for the magnetic $(\mathrm{m})$ and the surface $(\mathrm{s})$ contributions to SANS.

\section{Conclusions and prospects.}

Obviously SANS signals obtained from amorphous alloys have to be interpreted very cautiously, remembering that medium range effects, concentration and density fluctuations may be completely screened by the surface imperfection influence which can be suppressed by immersing the samples into suitable liquids to eliminate contrast with the outside. In the cases of ferromagnetic iron-base glasses, magnetic inhomogeneity may have even more greater effects and it is advisable to work with sufficiently strong applied magnetic fields if the magnetic contribution to SANS has to be removed. Polishing operations seem to result in just digging selected areas of the ribbon surface, then increasing the original imperfections and the corresponding SANS signal. It seems also that the majority of the magnetic inhomogeneity comes from the surfaces of the ribbon which may be related to the existence of a paramagnetic surface phase as has been already suggested [7]. 


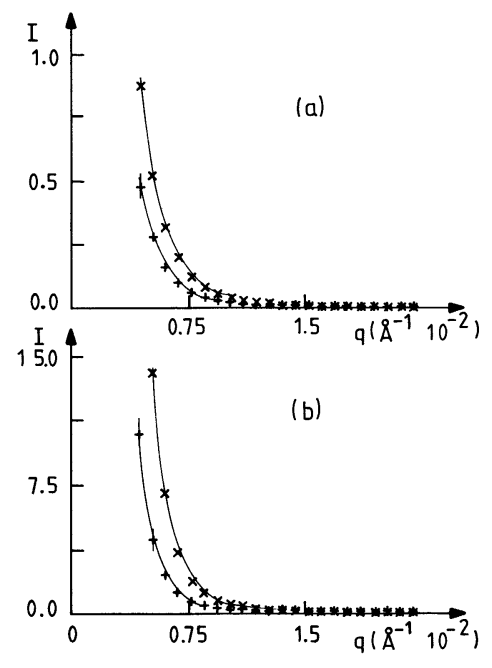

Fig. 3. - Comparison of the magnetic (b) and surface (a) contributions to SANS signals for samples in their as-cast state $(+)$ and after electrochemical polishing $(\times)$.

Now that the possibility is established of clearly separating the individual contributions to SANS intensity due to bulk, surface and magnetic inhomogeneity, there are reasonable prospects for various interesting investigations of amorphous alloys. These include phase separation in the amorphous state [8] (Fe Cr PC glasses of different compositions), characterization of surface transformation prior to bulk transformation on thermal treatments (embrittlement stage [7], crystallization) or the formation of magnetic clusters.

\section{Acknowledgments.}

The authors are grateful to $\mathrm{Ph}$. Mangin, L. Braganza and M. Roth for discussions and assistance during the experiments.

\section{References}

[1] Boucher, B., Chieux, P., Convert, P. and Tournarie, M., J. Phys. F 13 (1983) 1339.

[2] Nold, E., Steeb, S., Lamparter, P. and Rainer-Harbach, G., J. Physique Colloq. 41 (1980) C8-186.

[3] Yavari, A. R. and Desre, P., J. Phys. F 14 (1984) 291.

[4] Roth, M., J. Appl. Cryst. 10 (1977) 172.

[5] Rodemacq, B., Mangin, Ph. and Chamberod, A., Phys. Rev. B 30 (1984), in press.

[6] Wang, Z. X., Fong, M. Y., ShIE, X. Y., Roth, M. and Zhang, Z. Y., J. Magn. Magn. Mater. 28 (1982) 143.

[7] Janot, Chr., George, B., Tête, C. and Marchal, G., Res. Mechanica 11 (1984) 189.

[8] JANOT, Chr., Proceedings of the 5th RISO International Symposium on Metallurgy and Mat. Science. Eds. N. Hessel Angersen, M. Elchup, N. Hansen, D. Juul Jensen, T. Leffers, H. Lilholt, O. B. Pedersen and B. N. Singh (RISO National Lab., Roskilde, Denmark) 1984, p. 313. 